\title{
Fanconi anemia-D1 due to homozygosity for the BRCA2 gene Cypriot founder mutation: A case report
}

\author{
MARIA A. LOIZIDOU ${ }^{1}$, ANDREAS HADJISAVVAS ${ }^{1,2}$, GEORGE A. TANTELES $^{3}$, ELENA SPANOU-ARISTIDOU ${ }^{3}$, \\ KYRIACOS KYRIACOU $^{1,2}$ and VIOLETTA CHRISTOPHIDOU-ANASTASIADOU ${ }^{2,3}$ \\ ${ }^{1}$ Department of Electron Microscopy/Molecular Pathology; ${ }^{2}$ Cyprus School of Molecular Medicine, \\ Cyprus Institute of Neurology and Genetics; ${ }^{3}$ Department of Clinical Genetics, Makarios Medical Centre \\ and Cyprus Institute of Neurology and Genetics, Nicosia 1683, Cyprus
}

Received December 10, 2014; Accepted September 4, 2015

DOI: $10.3892 / 01.2015 .3852$

\begin{abstract}
Fanconi anemia (FA) is a rare disorder characterized by multiple congenital malformations, progressive bone marrow failure and susceptibility to malignancies. Biallelic mutations in the breast cancer 2, early onset (BRCA2) gene are responsible for the FA-D1 subgroup, which accounts for $\sim 3 \%$ of all the FA cases. Patients with biallelic BRCA2 mutations generally display a more severe phenotype, with earlier onset and increased incidence of leukaemia and other solid tumors, than other patients with FA. In the present report, the first Cypriot patient with FA-D1 is described, which is the fifth case of a homozygote for the same null allele reported thus far, and the third known case of neuroblastoma in association with FA-D1.
\end{abstract}

\section{Introduction}

Fanconi anemia (FA) is primarily a recessively inherited disorder typically associated with multiple congenital malformations, the most obvious of which involves the thumbs (1). Other features of FA may include microcephaly, developmental delay, microsomia, skeletal anomalies, pigmentary abnormalities, progressive bone marrow failure and susceptibility to acute myeloid leukaemia (AML) and other malignancies (1). Neuroblastoma is a neuroblastic tumor occurring almost exclusively in childhood (2). It is the third most common childhood cancer, after leukemia and brain tumors and is diagnosed annually with a prevalence of 1 case per 7,000 live births and

Correspondence to: Dr Violetta Christophidou-Anastasiadou, Department of Clinical Genetics, Makarios Medical Centre and Cyprus Institute of Neurology and Genetics, 6 International Airport Avenue, Nicosia 1683, Cyprus

E-mail: vanast@cing.ac.cy

Abbreviations: AML, acute myeloid leukaemia; FA, Fanconi anemia; IUGR, intrauterine growth restriction

Key words: biallelic BRCA2 mutation, neuroblastoma, Cyprus, genotype-phenotype correlation, Fanconi anemia an incidence of about 10.54 per 1 million per year in children $<15$ years (3). The median age at diagnosis is 19 months, and $90 \%$ of patients are diagnosed before the age of five years (2-4). Maternal and genetic factors have been associated with its pathogenesis. Treatment strategies depend on risk categories (low, intermediate and high), which are defined on the basis of stage of disease, age and the biological characteristics of the tumor (5). Neuroblastoma has only exceedingly rarely been associated with FA. FA is characterized by defects in DNA repair, hypersensitivity to DNA crosslinking agents and numerous chromosomal aberrations (1).

To date, homozygous or biallelic mutations have been reported in $\geq 15$ different genes, which lead to the known FA complementation groups (6). The proteins encoded by the FA genes cooperate in a common pathway, known as the 'Fanconi anemia-breast cancer (BRCA) pathway/network', which is essential for cellular resistance to DNA crosslinking agents $(7,8)$.

The FA-D1 subgroup results from germline biallelic mutations in the breast cancer 2, early onset (BRCA2) gene (9), and is estimated to account for $\sim 3 \%$ of all the FA cases (10). Patients within the FA-D1 subgroup generally display a more severe phenotype, with earlier onset and increased incidence of leukaemia and other solid tumors, than patients within other FA subgroups $(10,11)$.

Due to the rarity of FA-D1, reporting additional cases is critical in deciphering the full spectrum of malignancies associated with this subgroup, and for improving the understanding of the natural history of this disorder. In the present study, the first case of FA in Cyprus, which is due to a homozygous BRCA2 mutation, is reported.

\section{Case report}

A newborn female, which was the first child born to healthy non-consanguineous parents (a 25-year-old father and a 24-year-old mother), was referred to the Clinical Genetics Clinic of the Makarios Medical Centre (Nicosia, Cyprus) in April 2002, because of a history of multiple congenital anomalies present at birth. Review of the family history revealed two relatives with breast cancer from the paternal side (the grandmother and a great aunt), whereas the maternal family history was non-contributory. 
Antenatal ultrasound scans demonstrated oligohydramnios and intrauterine growth restriction (IUGR). The patient was born at 38 weeks of gestation, following an emergency $\mathrm{C}$-section, with a weight of $2 \mathrm{~kg}$ at birth. Initially, the patient was noted to present thumb abnormalities, including ectopic and hypoplastic right thumb and absent left thumb, in addition to microcephaly, microsomia, low-set ears, micrognathia, bifid tongue, dysplastic right hip, overriding toes and ectopic left kidney.

Karyotype analysis by Giemsa staining from peripheral blood revealed single cell abnormalities in 32 of 40 cells examined, including translocations, end-to-end fusions in three cells, deletions and spontaneous breaks, suggestive of a chromosomal breakage syndrome. Mitomycin $\mathrm{C}$ or diepoxybutane-induced studies were not performed.

At six months of age, the patient developed several petechiae and a hematoma of the right orbit as well as abdominal distention with associated hepatomegaly. The patient was subsequently admitted to the Pediatric Oncology Department of the Makarios Medical Centre where, following liver biopsy, the diagnosis of metastatic neuroblastoma was confirmed. Technetium-99 bone scan showed increased uptake at the skull and facial bones. The extent of metastatic disease was assessed by a metaiodobenzylguanidine (mIBG) scan, which revealed increased uptake at the skull, mandible and liver as previously observed on the MRI scan (stage IV metastatic neuroblastoma). The patient commenced chemotherapy, which included carboplatin and etoposide. However, the patient did not respond to the treatment, and succumbed to the disease at seven months of age.

The parents next experienced three first trimester spontaneous abortions, followed by a fifth pregnancy via in vitro fertilisation, which proceeded uneventfully until the 22nd week, when microcephaly was detected in the foetus. Based on the provisional diagnosis of FA of their first child, and the fact that the paternal grandmother was identified to be heterozygous for the c.8756delG BRCA2 mutation, the couple were counseled, and opted to undergo BRCA2 predictive genetic testing using standard protocols (12), which revealed that both parents were heterozygous for the same BRCA2 mutation [c.8756delG (p.Gly2919Valfs*8)]. The initial clinical hypothesis of FA was confirmed on an archived DNA from the index case, by the identification of the Cypriot founder BRCA2 mutation in a homozygous state. An amniocentesis was then performed, and the foetus was also demonstrated to be homozygous for this mutation. Consequently, the pregnancy was terminated. No further follow-ups were conducted.

\section{Discussion}

FA is a rare inherited genetic disorder with a prevalence of 1-5 cases/million (1). Cyprus has a population of $<1$ million habitants, and the present report constitutes the first documented case of FA-D1 on the island caused by a homozygous BRCA2 mutation.

FA is heterogeneous in its clinical manifestations and genetic defects (1). Howlett et al (9) were the first authors to report an association between FA-D1 and BRCA2 (also known as FANCD1), a gene implicated in the susceptibility to breast cancer. It has been previously demonstrated that patients with
FA who carry biallelic BRCA2 mutations display an earlier onset and a different spectrum of childhood malignancies than patients with FA who belong to other subgroups $(9,13,14)$. Previous studies on the FA-D1 subgroup have highlighted an increased risk of AML and acute T-cell lymphoma, in addition to solid tumors such as medulloblastoma and Wilms tumor, in patients with FA-D1 $(14,15)$. This observation is supported by previous epidemiological data and mouse model studies, which suggest that the normal function of FANCD1/BRCA2 is essential for the suppression of medulloblastoma and hematological malignancies $(16,17)$. Patients with FA-D1 exhibit the shortest average lifespan of all the FA subtypes (18). Cancer mortality for children with biallelic BRCA2 mutations is remarkably high, and approaches $100 \%$ by 5 years of age (10).

The phenotypic manifestations of FA are highly variable, even within specific complementation groups (1). The patient discussed in the present case report is the third case of neuroblastoma reported to date to be associated with FA-D1. The other two cases with biallelic BRCA2 mutations that have been previously reported correspond to a female born to Algerian first cousins, who was homozygous for the c.1320_1324del BRCA2 mutation (19), and a male who was compound heterozygous for the BRCA2 mutations c.1813dupA and c.631+2T $>\mathrm{G}$ (11). These two patients succumbed to FA-D1 at an extremely young age, similarly to the patient of the present case report, who was homozygous for the c.8756delG mutation in the exon 22 of the BRCA2 gene. This truncating BRCA2 mutation is a founder mutation in the Cypriot population (12), and has never been previously reported as a causative FA-D1 mutation, according to the Fanconi Anemia Mutation Database (http://www.rockefeller.edu/fanconi/mutate/).

Previous studies have suggested that homozygous BRCA2 mutations in humans may result in embryonic lethality (13). This hypothesis was supported by previous studies on BRCA2 homozygous knockout mice, which demonstrated embryonic lethality in the majority of cases $(20,21)$. However, previous reports of three individuals with FA-D1, who were homozygous for a BRCA2 mutation, refuted this initial hypothesis, and provided evidence that certain combinations of BRCA2 null alleles do not preclude foetal survival $(9,15,22)$.

To date, no homozygous cases for BRCA2 c.5946delT or c.771_775del5 mutations have been reported, despite their high prevalence among Ashkenazim and Icelanders ( 1.5 and $0.4 \%$, respectively) $(23,24)$.

The patient in the present report is the fifth case reported thus far of an individual with FA-D1 who is homozygous for the same null allele. The other four cases reported in the literature include the following patients: i) A BRCA2 homozygote for the c.1320_1324del mutation, who exhibited vertebral anomalies, anal atresia, cardiac defects, tracheoesophageal fistula and/or esophageal atresia, renal and radial anomalies, limb defects, Wilms tumor, neuroblastoma and a brain tumor, by three years of age (19); ii) a two-year-old patient who was homozygous for the c. $631+2 \mathrm{~T}>\mathrm{G}$ BRCA2 mutation, and presented with IUGR, imperforate anus, café-au-lait macules, microcephaly, failure to thrive and AML (15); iii) an individual homozygous for the c.1311_1314del BRCA2 mutation with an unknown phenotype (22); and iv) a male homozygote for the c.8488-1G $>$ A BRCA2 mutation, who reached adulthood (30 years of age) without developing cancer (9). 
The phenotype of the patient in the present case report was severe, and similarly to the case reported by Faivre et al (19), it included the development of infantile neuroblastoma. Therefore, despite the limited evidence, it can be hypothesized that the development of neuroblastoma in patients with FA-D1 is associated with the inheritance of two identical defective BRCA2 alleles, since two of the three cases of neuroblastoma associated with FA-D1 reported thus far (including the patient described in the present report) were homozygous for a deleterious BRCA2 mutation.

In conclusion, the present case report widens the spectrum of malignancies associated with FA-D1, and confirms the possibility of survival among patients with FA-D1 who exhibit certain mutational combinations in a homozygous state.

\section{References}

1. D'Andrea AD: Susceptibility pathways in Fanconi's anemia and breast cancer. N Engl J Med 362: 1909-1919, 2010.

2. Howlader N, Noone AM, Krapcho M, Neyman N, Aminou R, Waldron W, Altekruse SF, Kosary CL, Ruhl J, Tatalovich Z, et al (eds): SEER Cancer Statistics Review, 1975-2009 (Vintage 2009 Populations), National Cancer Institute. Bethesda, MD, http://seer.cancer.gov/csr/1975_2009_pops09/, based on November 2011 SEER data submission, posted to the SEER web site, April 2012.

3. Gurney JG, Ross JA, Wall DA, Bleyer WA, Severson RK and Robison LL: Infant cancer in the U.S.: Histology-specific incidence and trends, 1973 to 1992. J Pediatr Hematol Oncol 19: 428-432, 1997

4. London WB, Castleberry RP, Matthay KK, Look AT, Seeger RC, Shimada H, Thorner P, Brodeur G, Maris JM, Reynolds CP and Cohn SL: Evidence for an age cutoff greater than 365 days for neuroblastoma risk group stratification in the Children's Oncology Group. J Clin Oncol 23: 6459-6465, 2005.

5. Castleberry RP, Pritchard J, Ambros P, Berthold F, Brodeur GM, Castel V, Cohn SL, De Bernardi B, Dicks-Mireaux C, Frappaz D, et al: The International Neuroblastoma Risk Groups (INRG): A preliminary report. Eur J Cancer 33: 2113-2116, 1997.

6. Kitao $\mathrm{H}$ and Takata M: Fanconi anemia: A disorder defective in the DNA damage response. Int J Hematol 93: 417-424, 2011.

7. Mirchandani KD and D'Andrea AD: The Fanconi anemia/BRCA pathway: A coordinator of cross-link repair. Exp Cell Res 312: 2647-2653, 2006.

8. Venkitaraman AR: Tracing the network connecting BRCA and Fanconi anaemia proteins. Nat Rev Cancer 4: 266-276, 2004

9. Howlett NG, Taniguchi T, Olson S, Cox B, Waisfisz Q, De Die-Smulders C, Persky N, Grompe M, Joenje H, Pals G, et al: Biallelic inactivation of BRCA2 in Fanconi anemia. Science 297: 606-609, 2002.

10. Alter BP, Rosenberg PS and Brody LC: Clinical and molecular features associated with biallelic mutations in FANCD1/BRCA2. J Med Genet 44: 1-9, 2007.
11. Myers K, Davies SM, Harris RE, Spunt SL, Smolarek T, Zimmerman S, McMasters R, Wagner L, Mueller R, Auerbach AD and Mehta PA: The clinical phenotype of children with Fanconi anemia caused by biallelic FANCD1/BRCA2 mutations. Pediatr Blood Cancer 58: 462-465, 2012.

12. Hadjisavvas A, Charalambous E, Adamou A, Neuhausen SL, Christodoulou CG and Kyriacou K: Hereditary breast and ovarian cancer in Cyprus: Identification of a founder BRCA2 mutation. Cancer Genet Cytogenet 151: 152-156, 2004.

13. Offit K, Levran O, Mullaney B, Mah K, Nafa K, Batish SD, Diotti R, Schneider H, Deffenbaugh A, Scholl T, et al: Shared genetic susceptibility to breast cancer, brain tumors, and Fanconi anemia. J Natl Cancer Inst 95: 1548-1551, 2003.

14. Hirsch B, Shimamura A, Moreau L, Baldinger S, Hag-alshiekh M, Bostrom B, Sencer S and D'Andrea AD: Association of biallelic BRCA2/FANCD1 mutations with spontaneous chromosomal instability and solid tumors of childhood. Blood 103: 2554-2559, 2004.

15. Wagner JE, Tolar J, Levran O, Scholl T, Deffenbaugh A, Satagopan J, Ben-Porat L, Mah K, Batish SD, Kutler DI, et al: Germline mutations in BRCA2: Shared genetic susceptibility to breast cancer, early onset leukemia, and Fanconi anemia. Blood 103: 3226-3229, 2004.

16. Friedenson B: The BRCA1/2 pathway prevents hematologic cancers in addition to breast and ovarian cancers. BMC Cancer 7 : $152,2007$.

17. Frappart PO, Lee Y, Lamont $\mathbf{J}$ and McKinnon PJ: BRCA2 is required for neurogenesis and suppression of medulloblastoma. EMBO J 26: 2732-2742, 2007.

18. Wang W: Emergence of a DNA-damage response network consisting of Fanconi anaemia and BRCA proteins. Nat Rev Genet 8: 735-748, 2007.

19. Faivre L, Portnoi MF, Pals G, Stoppa-Lyonnet D, Le Merrer M, Thauvin-Robinet C, Huet F, Mathew CG, Joenje H, Verloes A and Baumann C: Should chromosome breakage studies be performed in patients with VACTERL association? Am J Med Genet A 137: 55-58, 2005.

20. Ludwig T, Chapman DL, Papaioannou VE and Efstratiadis A: Targeted mutations of breast cancer susceptibility gene homologs in mice: Lethal phenotypes of Brca1, Brca2, Brca1/Brca2, Brca1/p53, and Brca2/p53 nullizygous embryos. Genes Dev 11: 1226-1241, 1997

21. Hakem R, de la Pompa JL and Mak TW: Developmental studies of Brca1 and Brca2 knock-out mice. J Mammary Gland Biol Neoplasia 3: 431-445, 1998

22. Ameziane N, Errami A, Léveillé F, Fontaine C, de Vries Y, van Spaendonk RM, de Winter JP, Pals G and Joenje H: Genetic subtyping of Fanconi anemia by comprehensive mutation screening. Hum Mutat 29: 159-166, 2008.

23. Roa BB, Boyd AA, Volcik K and Richards CS: Ashkenazi Jewish population frequencies for common mutations in BRCA1 and BRCA2. Nat Genet 14: 185-187, 1996.

24. Johannesdottir G, Gudmundsson J, Bergthorsson JT, Arason A, Agnarsson BA, Eiriksdottir G, Johannsson OT, Borg A, Ingvarsson S, Easton DF, et al: High prevalence of the 999del5 mutation in icelandic breast and ovarian cancer patients. Cancer Res 56: 3663-3665, 1996. 